$21-2-1$

7 月 21 日

$9: 15$

第 2 会場

\title{
The Optimization Analysis of Moments
}

\section{in the Combinatorial Model System}

We have previously proposed the concept of the "combinatorial model system" to analyse the relations between the structure and the metabolism which were expressed in linear multicompartment models, and introduced the "combinatorial approach" to calculate the parameters such as availability and clearance (Chem. Pharm. Bull. 36(3)1041-1052,1988). Here we analysed the fundamental properties of moments in the combinatorial model system.

We defined the unilateral single-inlet-single-outlet system as the "conformation" and denoted as C. For any conformation $C$, we can naturally define the mean residence time MRT(C) and the variance of residence time VRT(C) as the statistical moments of the output function for the input delta function.

First, we proved the fundamental relations for moments. For conformations $\mathrm{C}_{1}$ and $\mathrm{C}_{2}$, we observed the combination in series $\mathrm{C}_{1} * \mathrm{C}_{2}$, and the one in parallel $\mathrm{C}_{1}+\mathrm{C}_{2}$. Then we showed $\operatorname{MrT}\left(\mathrm{C}_{1} * \mathrm{C}_{2}\right)=\operatorname{MrT}\left(\mathrm{C}_{1}\right)+\operatorname{MrT}\left(\mathrm{C}_{2}\right) \quad(1), \operatorname{VRT}\left(\mathrm{C}_{1} * \mathrm{C}_{2}\right)=\operatorname{VRT}\left(\mathrm{C}_{1}\right)+\operatorname{VRT}\left(\mathrm{C}_{2}\right)$ (2), $\operatorname{MRT}\left(\mathrm{C}_{1}+\mathrm{C}_{2}\right)=\mathrm{s}_{1} \operatorname{MRT}\left(\mathrm{C}_{1}\right)+\mathrm{s}_{2} \operatorname{MRT}(\mathrm{C}) \quad(3)$, and $\operatorname{VRT}\left(\mathrm{C}_{1}+\mathrm{C}_{2}\right)=$ $\mathrm{s}_{1} \operatorname{VRT}\left(\mathrm{C}_{1}\right)+\mathrm{s}_{2} \operatorname{VRT}\left(\mathrm{C}_{2}\right)+\mathrm{s}_{1} \mathrm{~s}_{2}\left\{\operatorname{MRT}\left(\mathrm{C}_{1}\right)-\operatorname{MRT}\left(\mathrm{C}_{2}\right)\right\}^{2}(4)$, where $s_{i}=f_{i} /\left(f_{1}+f_{2}\right)$ and $f_{i}$ is the availability of $C_{i}$ for $i=1$ and 2). Using these fomulae for "conformations" repeatedly we can calculated the moment of an arbitrarily complicated system in an arithmetical manner. For example, (4) could be easily generalised as follows, $\operatorname{VRT}\left(\sum_{i=1} \mathrm{C}_{i}\right)$ $=\sum_{i=1} \operatorname{VRT}\left(C_{i}\right)+\sum_{i=1}^{n} \operatorname{MRT}\left(C_{i}\right)^{2} s_{i}-\left\{\sum_{i=1}^{n} \operatorname{MRT}\left(C_{i}\right) s_{i}\right\}^{2}$

Secondly, we solved the optimization problems in fundamental compartment systems. Let the total sum of intrinsic clearances in the system be constant (=CLint), and 
the inlet blood flow and the total sum of volumes in the system be also constant ( $=Q$ and $V$ respectively), then we obtained several inequalities for the range of moments.

1) For two compartments $\mathrm{C}_{1}$ and $\mathrm{C}_{2}$,

$$
1 /(1+R / 2) V / Q \leqq M R T\left(C_{1} * C_{2}\right) \leqq V / Q
$$

$1 /\left\{\left(1+p_{1} R\right)^{2}+\left(1+p_{2} R\right)^{2}\right\} \leqq \operatorname{VRT}\left(C_{1} * C_{2}\right) \leqq(V / Q)^{2}$, where $R=C L_{\text {int }} / Q$, and $r_{1} /\left(1+p_{1} R\right)^{2}=r_{2} /\left(1+p_{2} R\right)^{2}$

[Here $p_{i}$ and $q_{i}$ are the partitions of unity which correspond to the partitions of $\mathrm{CL}_{\text {int }}$ and $\mathrm{V}$ to $\mathrm{C}_{i}$ respectively for $i=1$ and 2.]

2) Especially if $r_{1}=r_{2}$, then ( 7 ) reduced to $1 / 4\left\{1 /(1+R)^{2}+1\right\}(V / Q)^{2} \leqq \operatorname{VRT}\left(C_{1} * C_{2}\right) \leqq(V / Q)^{2}$

3) If $r_{i}=1 / n(i=1, \ldots, n)$, then 1) was generalized as $1 /(1+R / n)(V / Q) \leqq M R T\left(C_{1} * \ldots * C_{n}\right) \leqq_{1} /\{(1+R)+(n-1)\} / n(V / Q)(9)$ and $(1 / n)\left\{1 /(1+R / n)^{2}\right\}(V / Q)^{2} \leqq \operatorname{VRT}\left(C_{1} * \ldots * C_{n}\right)$

$\leqq(1 / n)\left\{1 /(1+R)^{2}+n-1\right\}(V / Q)^{2}$

4) If $\mathrm{CL}_{\text {int }}=0$, then $\operatorname{MrT}\left(\mathrm{C}_{1} * \ldots * \mathrm{C}_{\mathrm{n}}\right)=\mathrm{V} / \mathrm{Q}$

and $(V / Q)^{2}(1 / n) \leqq \operatorname{VRT}\left(C_{1} * \ldots * C_{n}\right)^{n} \leqq(V / Q)^{2}$

5) If $\mathrm{CL}_{\text {int }}=0$, then $\operatorname{MRT}\left(\mathrm{C}_{1}+\ldots+\mathrm{C}_{\mathrm{n}}\right)=\mathrm{V} / \mathrm{Q}$

and

$$
(\mathrm{V} / \mathrm{Q})^{2} \leqq \operatorname{VRT}\left(\mathrm{C}_{1} * \ldots * \mathrm{C}_{\mathrm{n}}\right)<\infty
$$

etc. These results can be taken into consideration when we construct multicompartment model system to evaluate the time-concentration curve for any drugs. Moreover we can apply these results to understand the principle of the structural growth of the various biological systems from the viewpoint of optimization. 